\title{
Reticulated Roof Structures Optimisation Based of Triangular and Quadrilateral Planar Panels
}

\author{
Anna Stefańska
}

Warsaw University of Technology, Warsaw, Poland, anna.stefanska2@pw.edu.pl

\begin{abstract}
The search for the form optimization of reticulated roof structures is a significant aspect in Architectural Engineering and Construction section. It consists of reflecting the intended aesthetic effect as well as an attempt to choose the most suitable technical solutions. Therefore the divisions of reticulated structures should be determined to pursuit of structural, material and technique of fabrication advancement. In contemporary construction practice, understanding how curved shapes describe the form becomes an significant design aspect. Structural divisions of free-formed canopies should be solved in architectural and structural design simultaneously at an early stage of designing. The choice of proper designing method becomes a complicated process, requiring the ability to selecting type of production and rationalize technical solutions mainly due to the computer aided design supported by algorithmic tools. The paper research analyzes curvilinear structures of canopies in search of optimal structures of geometrical divisions. Case study is based on reticulated roof structures with triangular and quadrilateral panelization. In recent twenty years, the most common and accessible solutions for free-form canopies are triangular divisions due to the ability to use flat glass panels. Panelized Quadrilateral surfaces, facilitate the fabrication process in many aspects, surpassing triangular panels. Their main disadvantage was the design of quadrilateral flat panel mesh. The finding of the study conclude assets and flows of both methods of shaping the geometry of reticulated roof structures based on material and technology of fabrication aspects. The study conclude that the crucial designing method is to determine the manufacturing technology in the early stage of architectural optimization.
\end{abstract}

(c) 2020 The Authors. Published by Budapest University of Technology and Economics \& Diamond Congress Ltd Peer-review under responsibility of the Scientific Committee of the Creative Construction Conference 2020.

Keywords: creative designing, generative designing, grid canopies, structural optimization, topology optimization

\section{Introduction}

In the 21st century, a change in the way of designing in Architectural, Engineering and Construction sector is noticeable. Sustainable Development adopted by the United Nations Assembly, influences on construction development mainly in natural resources usage without destroying natural ecosystems. It results in the implementation of optimisation methods and tools into designing, construction and exploitation phase of buildings life. It is visible in supervising of the entire production process, from BIM environment designing, through controlling the construction process, construction productivity, optimizing the material and shape with unprecedented precision [1]. The process resembles the designing approach of the medieval craftsman [2]. The dynamically progressing digitization is now "filtering" the design techniques and methods associated with structures optimisation. It is commonly used for Architectural Design Optimisation (ADO) [3]. Increased use of parametric design and simulation of building parameters enables optimization of, among other, material, costs, and time, for construction and subsequent maintenance, reducing the carbon footprint. In design practice, however, architects and structural designers still encounter significant difficulties in using algorithmic designing by: "insufficient knowledge of optimization based on multi-variant simulations, use of inefficient optimization methods based on genetic 
algorithms, lack of modern, easy-to-use optimization tools and lack of integration of optimization into architectural design." [4].

Computer based methods of digital modeling in designing free geometries structures improve not only the aesthetic quality but also the efficient use of materials [5]. It provides new possibilities in a creative search for "eco-efficient" architectural forms and technical solutions. Thanks to the availability of advanced, generative techniques as well as engineering methods, achievements in structural optimisation have remarkable outputs. Designers, thanks to computer aided design, can mimic forms found inspired by nature nature[6]. This trend in architecture, called biomimetic, can be used on different designing levels, from imitating the patterns found in nature to understanding natural ecosystems behaviour and implementing them into the building scheme. The design process is already at the concept stage dictated by the fabrication method. The development of free-form architectural designs has intensified the development of technologies which can shape the form differently. An essential issue in the problems undertaken by designers is: (1)the use of digital tools, with the use of biomimetics and mathematical algorithms, in search of optimal shapes and behavioural systems; (2) ways of fabrication of building elements, adjusted with appropriate selection of shape and preparation of elements for easy assembly; (3) search for the minimization of energy required to fabrication, the use of environmentally friendly materials, or the least amount of environmental degradation (including carbon footprint).

\section{Background}

Mathematical algorithms based on proportionality requirements analyse various variant solutions in order to find the optimal free-form geometry. It is thought-provoking particularly for prefabrication which nowadays is increasingly characterized by the idea of postfordism [7]. Striving for unification does not exclude the creative search for individual solutions. The use of the computational capacity of computers has made it possible to test many concepts based on many factors optimisation, especially designed with the use of laws of nature. Learning those rules has become the basis for formal experiments. These, in turn, form the basis for the designers [8]. Current research on structures with free shapes is the result of inspiration from natural forms found in nature. Biomimetic inspiration and the search for algorithms that describe its principles seem to be justified by fact that the processes governing living organisms are a matter of survival [9]. It is visible in the architectural realizations of famous architectural studios all over the world. This paper raises two main courses of the free-formed canopy panels shaping: using triangular panels (Fig. 1.) and quadrilateral panels (Fig. 2).

\section{Literature review}

Grid-shell geometry named also as retirculated surface structure is an attempt to perform simplified computational models of curvilinear structures [5]. They are the result of numerical methods of dynamic relaxation used in form-finding [10], alongside such optimisation methods as the force density method [11], particle spring system [12] or reference strategy [13]. The principle of form-finding can be illustrated as a process of shaping structures, with an assumed load, as physical models made by A. Gaudi or F. Otto in previous century. It is: "finding an (optimal) shape of a (form-active structure) that is in (or approximates) a state of static equilibrium" [14]. In designing free-form canopies, which are mostly doubly-curved structures, there must be a compromise between aesthetics and technology [15]. Planar glass panels filling the structural grid to achieve material savings become a technological requirement. The aesthetic requirement, on the other hand, is smoothness of the surface division (possibly without sharp edges) [16].

While analyzing the research literature, some factors of material minimization and affordability of fabrication process were found. Examples of comparison of freeform grid-shell structures with triangular and quadrilateral panels are presented in Table 1. The three most important factors influencing the selection of panels with quadrilateral or triangular geometry are distinguished: design method, the technology of execution, and architectural quality. The presented conclusions were made based on the analysis of research works from recent years[17,5,15,18]. 

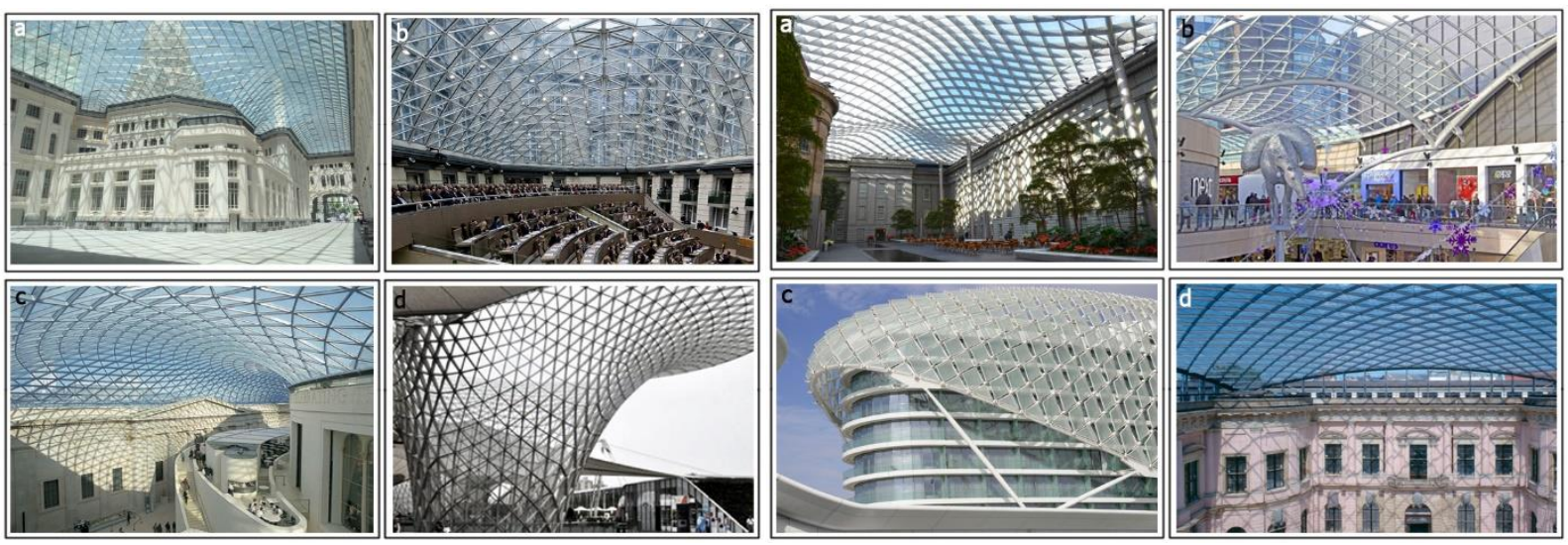

Fig. 1. (left)Free-form grid-shell canopy with mesh triangular panelization: (a)Matrid City Hall; (b) Meeting Hall Flemish Council in Belgium; (c) British Museum of Art; (d) Shanghai EXPO pavilion; Fig. 2.(right)Free-form grid-shell canopy with mesh rectangular panelization: (a) Kogod Courtyard w Smithnonian; (b) Trinity w Leed mall centre; (c) Yas Island Hotel in Abu Dhabi; (dGerman Historical Museum in Berlin

Table 1. A comparison of characteristics of free-form canopies in triangular and quadrilateral panels.

\begin{tabular}{|c|c|c|}
\hline & Triangular Panels & Rectangular panels \\
\hline Design method & $\begin{array}{l}\text { + easy subdivision of double-curved } \\
\text { geometries into any flat triangular } \\
\text { panels }\end{array}$ & $\begin{array}{l}\text { - difficulty in developing flat-panel geometries on a quadrangle: } \\
\text { when developing quadrilateral double-sided panels, further } \\
\text { technological problems arise, such as thermal deformability; } \\
\text { in the case of developing flat panels, designers often had to } \\
\text { compensate for problems in achieving the correct curvature in } \\
\text { the outer part of the cover (e.g., Courtyard Coord at } \\
\text { Smithsonian) }\end{array}$ \\
\hline $\begin{array}{l}\text { the technology } \\
\text { of execution }\end{array}$ & $\begin{array}{l}\text {-difficulty in making joints in which six } \\
\text { bars merge at different angles } \\
\text {-more waste glass than in } \\
\text { quadrilateral panels }\end{array}$ & $\begin{array}{l}\text { + ease of fabrication of joints where only } 4 \text { rods merge } \\
+ \text { minimizing the amount of waste of covering material of } \\
\text { rectangular panels (comparing to triangular ones) }\end{array}$ \\
\hline $\begin{array}{r}\text { architectural } \\
\text { quality }\end{array}$ & $\begin{array}{l}\text { - a larger ratio of the surface area of } \\
\text { the rod structural elements in } \\
\text { comparison to the quadrilateral } \\
\text { grids, which is equivalent to less } \\
\text { translucency }\end{array}$ & $\begin{array}{l}\text { - higher translucency and interior illumination thanks to a } \\
\text { smaller ratio of structural elements is a covering material. }\end{array}$ \\
\hline
\end{tabular}

\section{Research methodology}

The selected models represented the construction of pavilion canopy. The area of each geometry is $900 \mathrm{~m}^{\wedge} 2$. The paper compares the structures designed as free-forms curvilinear geometries using the Delaunay triangulation, regular triangle and quadrilateral divisions. The geometries with Delaunay triangulation divisions we optimised at first, because of random selections of nodes and bars lenght without designers interfere. The resultant geometry with the lowest total weight of the structure was the basis for subsequent more in-depth studies. A case study of reticulated structure with regular: triangular and quadrilateral divisions comparison was conducted, based on the parameters from initial Delaunay triangulation analysis: the total length of all bar, same length of single bars and number of joints.

In the geometry generating process of bar meshes, geometry and material optimisation softwares were used. Grasshopper /Rhinoceros was used in form-finding method, to create a catenary model and dynamic relaxation (Kangaroo2 and Karamba plug-ins was used to imitate physical forces and adjustment of the structure curvature and initial material optimization. Structural optimization was performed in Robot Structural Analysis. Thanks to adopting generative tools geometries are considered to distribute loads in the structures more efficiently than mathematically determined shapes such as parabola. The differences between the two curves are almost invisible to notice, but allow a significant optimization of material applying. Such research were noticeable in A. Gaudi's research(Fig. 3). The purpose of this numerical method is to find a geometry in which all forces are in equilibrium, allowing the minimum area (length) of the structure to be found.In the structures under study, the use of dynamic relaxation allows for significant minimization of materials e, which is visible in earlier studies of curvilinear structures [19]. 
Two-stage analyses of various grid canopy geometries were carried out: Study 1- analysis of the structural mesh based on Delaunay triangulation, (the analysed geometries were previously developed within the author's research); Study 2- comparative study of topological changes of the grid-shell on triangular and quadrilateral regular division, according to the guidelines parameters from Study 1.

\section{Results and findings}

\subsection{Study I- reticulated structure optimisiation basing on mesh Delaunay tiangular divisions}

Table 2. Results of Study I- analyzed Delaunay mesh grid-shell

\begin{tabular}{cccccc}
\hline Variant & $\begin{array}{c}\text { The } \\
\text { curvature } \\
\text { height to the } \\
\text { support } \\
\text { span ratio }\end{array}$ & $\begin{array}{c}\text { Adapted profile } \\
\text { (type and } \\
\text { dimensions in } \\
\mathrm{mm} \text { ) }\end{array}$ & $\begin{array}{c}\text { Maximum } \\
\text { deformatio } \\
\mathrm{n}[\mathrm{cm}]\end{array}$ & $\begin{array}{c}\text { Total } \\
\text { length of } \\
\text { the rods } \\
{[\mathrm{m}]}\end{array}$ & $\begin{array}{c}\text { Total } \\
\text { weight } \\
{[\mathrm{kg}]}\end{array}$ \\
\hline $\mathrm{A}$ & $1 / 5$ & TRON 139x5,0 & 6,2 & 1376,14 & 22865 \\
$\mathrm{~B}$ & $1 / 4$ & TRON 139x4,0 & 6,6 & 1390,69 & 18623 \\
$\mathrm{C}$ & $1 / 3$ & TRON 139x4,0 & 5,9 & 1420,48 & 19022 \\
\hline
\end{tabular}

A comparison of freeform structure systems showed that the average total mass decreased as the total height of the srtucture increases. The average total weight of the structures was $20170 \mathrm{~kg}$. The most optimal variant (with the lowest total weight) was Variant $B$. The total weight of this arrangement is 18,623 $\mathrm{kg}$ (with the roofing area of $963.41 \mathrm{~m}^{2}$ ).

Study I- summary, the following parameters were observed while analyzing the optimal variant B:

- Finding 1: The average total length of all members was $1395.77 \mathrm{~m}$;

- Finding 2: the length of the members did not exceed $5.0 \mathrm{~m}$;

- Finding 3: the sum of all nodes was 203.

\subsection{Study II- reticulated structure optimization basing on regular quadrilateral and triangular divisions}

Study II aimed to identify the most beneficial divisions of quadrilateral and regular triangular meshes, shaped according to the weight minimization and fabrocation process. Geometries were generated basing of conclusions of Study I.

Case study of the second phase consists of 18 covering structures, divided into three groups according to the total length of all bars, a single bar length of about $5 \mathrm{~m}$ and a total of all nodes of around 203. The resulting geometries (Fig.3-4.) show a significant difference in the density of the mesh. Also, the smoothness of the canopy varies between the geometries.
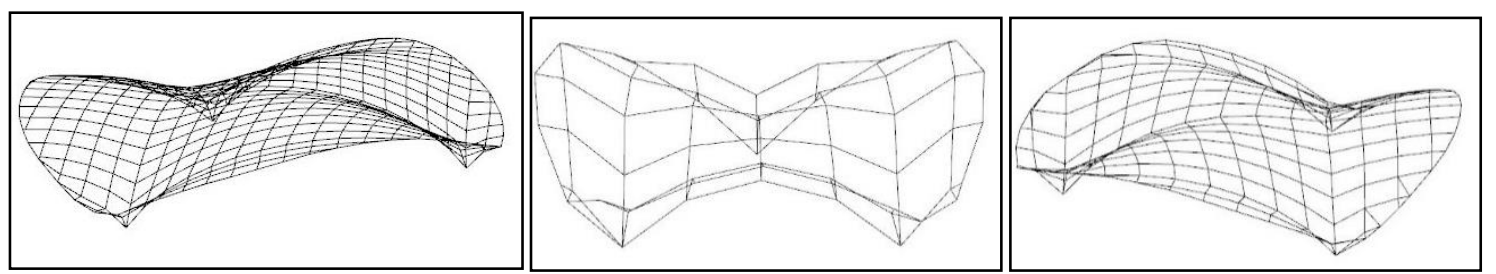

Fig. 3. PQ geometries generated according Findings: (a) fixed total length in the grid-shell $1390 \mathrm{~m}$; (b) fixed length of each bar $5 \mathrm{~m}$; (c) fixed number of joints
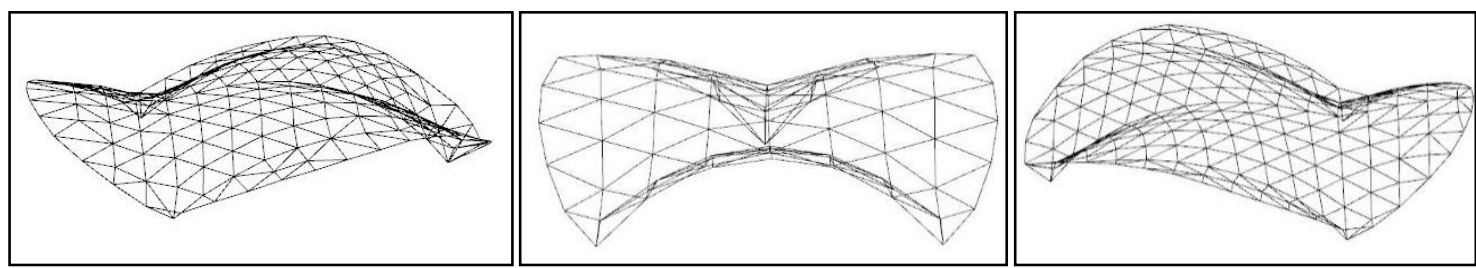

Fig. 4. Triangular panels geometries generated according Finding: (a) fixed total length in the grid-shell 1390 m; (b) fixed length of each bar $5 \mathrm{~m}$; (c) fixed number of joints 
Proceedings of the Creative Construction e-Conference (2020) 014

Available online at e-2020.creative-construction-conference.com/proceedings/

Table 3. Results of Study II- analysis of regular rectangular and triangular meshes of the canopy

\begin{tabular}{|c|c|c|c|c|c|c|c|c|c|c|}
\hline \multirow{2}{*}{$\begin{array}{c}\text { The } \\
\text { curvature } \\
\text { height to } \\
\text { the } \\
\text { support } \\
\text { span ratio }\end{array}$} & \multicolumn{3}{|c|}{$\begin{array}{l}\text { Finding } 1 \text { - fixed total length in the } \\
\text { grid-shell 1390 } \mathrm{m}\end{array}$} & \multicolumn{3}{|c|}{$\begin{array}{l}\text { Finding } 2 \text { - fixed length of each } \\
\text { bar } 5 \mathrm{~m}\end{array}$} & \multicolumn{4}{|c|}{ Finding 3-fixed number of joints } \\
\hline & $\begin{array}{c}\text { Planar } \\
\text { quadrilateral } \\
\text { grid }\end{array}$ & \multicolumn{2}{|c|}{ Triangular grid } & $\begin{array}{c}\text { Planar } \\
\text { quadrilateral } \\
\text { grid }\end{array}$ & \multicolumn{2}{|c|}{ Triangular grid } & \multicolumn{2}{|c|}{$\begin{array}{c}\text { Planar } \\
\text { quadrilateral grid }\end{array}$} & \multicolumn{2}{|c|}{ Triangular grid } \\
\hline $1 / 5$ & 24684 & 1.4. & 22128 & 26987 & 2.4 . & 28344 & 3.1. & 26952 & 3.4 & 33618 \\
\hline $1 / 4$ & 18310 & 1.5 & & 24501 & 2.5 . & & 3.2 . & & 3. & 25662 \\
\hline $1 / 3$ & 16696 & 1.6 & 22609 & 25310 & 2.6. & 20398 & 3.3. & 22683 & 3.6. & 23697 \\
\hline
\end{tabular}

\section{Findings}

The lowest total weight of the structure was achieved in quadrilateral panels Variant 1.3 (with a total bar length of $1390 \mathrm{~m}$ ) with a total weight $16696 \mathrm{~kg}$. Among the variants with triangular divisions, Variant 2.6, with a total weight of $20,398 \mathrm{~kg}$, was the most lightweight. The difference in best quadrilateral and triangular variants was almost 4 tons. However, triangular panelled reticulated structures are still more frequently chosen structures. It is due to technological difficulties from the design stage to the execution stage.

The technology of making PQ structures is more demanding in terms of technology and design than that triangular panels (for which finding a plane passing through all three points is remarkably easy). It is visible in the canopy structure of Kogod Courtyard, where a smooth surface of the roofing was obtained only from the inside of the courtyard, while on the outer side had a significant fragmentation of the surface. Therefore, the manufacturing technology and structural design aspects are the main points in interdisciplinary generative design. Architectural Design Optimization (ADO) in the initial designing phase implement the construction methods as equally important factors as aesthetic appearance. Choosing the fabrication methods for instance if the nodes are made by traditional welding (where the minimum number of welded elements is essential) or by 3D printing (where the most crucial question is to minimize the usage of the material and printing time). As highlighted in literature analyses, it was noticed that the construction of nodes connecting only 4 rods increases the amount of sunlight inside. By comparing the best results of structures with regular quadrilateral and triangular panels, a significant reduction in weight is visible in favour of the PQ. However, comparing the number of nodes in both structures (where the nodes give the most of shadows), there is a vast difference. The quadrilateral Variant 1.3. has 452 nodes, while the triangular Variant 2.6. only 75. Many aspects, such as the number and type of manufacturing of the nodes, become a fundamental aspect of designers' work. Comparing the result of the structure with the Delaunay triangulation divisions and the best variants in the regular quadrilateral and triangular divisions showed significant differences, which may ultimately affect the choice of a particular geometry due to technological factors, rather than merely optimizing the weight of the structure. Tabel 4. presents comparison of the main differences in structural data between the best geometries in each type of mesh divisions in canopies.

Table 4. comparison of choosen factors of types of reticulated mesh divisions

\begin{tabular}{cccc}
\hline factor & $\begin{array}{c}\text { Delaunay } \\
\text { Triangulation }\end{array}$ & $\begin{array}{c}\text { Regular } \\
\text { rectangular }\end{array}$ & $\begin{array}{c}\text { Regular } \\
\text { triangular }\end{array}$ \\
\hline Weight $[\mathrm{kg}]$ & 18623 & 16696 & 20398 \\
Total length $[\mathrm{m}]$ & 1390 & 1390 & 858,57 \\
Length of individual rods[m] & $1-5$ & 2,3 & 5 \\
Number of joints & 203 & 452 & 75 \\
\hline
\end{tabular}

\section{Conclusion and discussion}

Thanks to new computer aided optimization tools, designers undertake attempts in creating more advanced structures, such as free-formed reticulated canopies. The choice of materials and technologies becomes the key to broadening the boundaries of the knowledge and perception skills. The new possibilities of computational design, change multidisciplinary environment. In the case of designing a usage of relatively simple tools benefits in in-depth optimisation process. Obtaining efficient structural divisions of grids becomes an interdisciplinary task to be solved in architectural-constructional and manufacturing aspect. The selection of the manufacturing techniques influences on the process of designing. The ability to implant the type of the production and connected with it cost optimisation, become 
a crucial factor in choosing specific technical solutions in the construction phase. Searching for aesthetic effects and waste reduction can be attained due to the algorithmization of design tools. Due to multiple boundary conditions, which vary in each designing process there is never one best solution for all the designing and construction obstacles. The algorithmic design allows to correct assumptions: "this also includes the usefulness of the algorithm as a tool to verify design concepts and the talent of their creators." [20]. The author intended that the ideas presented in this work encourage further investigation in the field.

\section{References}

[1] S. Dixit, S. N. Mandal, J. V. Thanikal et al., Evolution of studies in construction productivity: A systematic literature review (20062017), Ain Shams Engineering Journal. https://doi.org/10.1016/j.asej.2018.10.010

[2] A. Penn, Fabricate 2011, Making Digital Architecture, red., R, Glynn, B. Sheil p. 12-13,2017. https://doi.org/10.2307/j.ctt1tp3c6d.4

[3] T. Wortmann, G. Nannicini, Introduction to Architectural Design Optimisation, City Networks, Springer, 2017. https://doi.org/10.1007/978-3-319-65338-9_14

[4] T. Wortmann, Efficient, Visual, and Interactive Architectural Design Optimization with Model-based Methods, Praca doktorska wydana w Songapore University of Technology and Design, Singapur, 2018, [źródło: https://doi.org/10.13140/RG.2.2.15380.55685, dostęp 19.01.2019]

[5] S.H. Dyvik, M. Luczkowski, J.H. Mork, A. Ronnquist, B. Manum, Design of freeform gridshell structure-Simplifying the parametric workflow, IABSE Symposium 2019 Guimaraes, Portugal

[6] Benyus, J. (1997). Biomimicry, Innovation Inspired by Nature. New York: William Morrow. ISBN 978-0-06-053322-9

[7] M. Piore, Ch. Sabel, The Second Industrial Divide, New York, Basic Books, 1984

[8] E, Gawell, A. Stefańska, Idea fabrykacji elementów strukturalnych w kształtowaniu współczesnych pawilonów, „Zeszyty Naukowe Vistula", Warszawa, 2018, ISSN 2353-2688

[9] R. Finsterwalder, Form Follow Nature. History of nature as a model for design in engineering, architecture and art, Springer, Wiedeń i Nowy York, 2011. https://doi.org/10.1515/9783990437056-007

[10] V. Alic, K. Persson, Form finding with dynamic relaxation and isogemetric membrane elements, Computer methods in applied mechanics and engineering 300 (2016) p.734-747. https:/dx.doi.org/10.1016/j.cma2015.12.009

[11] H.J. Schek, The force density method for form-finding and computation of general networks, Comput Methods Appl. Mech. Engrg.3(1)(1974)p. 115-134. https://doi.org/10.1016/0045-7825(74)90045-0

[12] A. Kilian, J. Ochsendorf, Particle-spring system for structural form finding, J.Int. Assoc. Shell Spal. Struct., 148 (2005), p.77

[13] K.U. Bletzinger, E. Ramm, A general finite element approach to the form finding of tensile structures by the updated reference strategy, Int. J.Space Struct, 14 (2) (1999) p. 131-145. https://doi.org/10.1260/0266351991494759

[14] W.J. Lewis, Tension structures, Form and Behaviour, Thomas Telford, London, 2003. https://doi.org/10.1680/tsfab.61736.023

[15] R.Mesnil, C. Douthe, O. Baverel, Non-standard patterns for gridshell structures: Fabrication and structural optimisation, Journal of the International Association for shell and special structure, 2017. https://doi.org/10.20898/j.iass.2017.194.893

[16] J. Wallner, H. Pottmann, Geometric computing for freeform architecture. J.Math.Industry 1, 4 (2011). https://doi.org/10.1186/21905983-1-4

[17] M. Święciak, Freforms in architekcture Shaping of discrete, doubly-curved grid-shells in planar quadrilateral topology using the bottom-up approach, PhD thesis, Wroclaw University of Technology, Wroclaw ,2019

[18] R. Avelino, O. Baverel, A. Lebea, Design Strategies for Gridshells with Singularities, Journal of the International Association for shell and special structure, 2019. https://doi.org/10.20898/j.iass.2019.201.023

[19] A. Stefańska, E. Gawell, W. Rokicki, The Delunay Triangulation in the design of architectural gridshells, Proceedings of the Creative Construction Conference 2019, Budapest, 2019, p. 132-138. https://doi.org/10.3311/ccc2019-020

[20] W. Bonenberg, M. Giedrowicz, K. Radziszewski, Współczesne projektowanie parametryczne w architekturze (eng. Contemporary parametric design in architecture), Wydawnictwo Politechniki Poznańskiej, Poznań, 2019. ISBN 978-83-7775-548-8 